\title{
What is a Highly Popular Post? Popularity Benchmark Models for Posts on Facebook Pages
}

\author{
Pin Luarn ${ }^{1}$, Ya-Cing Jhan ${ }^{2}$, Hong-Wen Lin ${ }^{3}$ \\ ${ }^{\prime}$ Professor, Department of Business Administration, National Taiwan University of Science and Technology, Taipei City, \\ Taiwan (R.O.C.),E-Mail: luarn@mail.ntust.edu.tw \\ ${ }^{2} P h . D$. Candidate, Department of Business Administration, National Taiwan University of Science and Technology, \\ Taipei City, Taiwan (R.O.C.), E-Mail: kelly6824@hotmail.com \\ ${ }^{3}$ Associate Professor, Department of International Trade, Chinese Culture University, Taipei City, Taiwan (R.O.C.) \\ E-Mail:woodylin34@hotmail.com (Corresponding author)
}

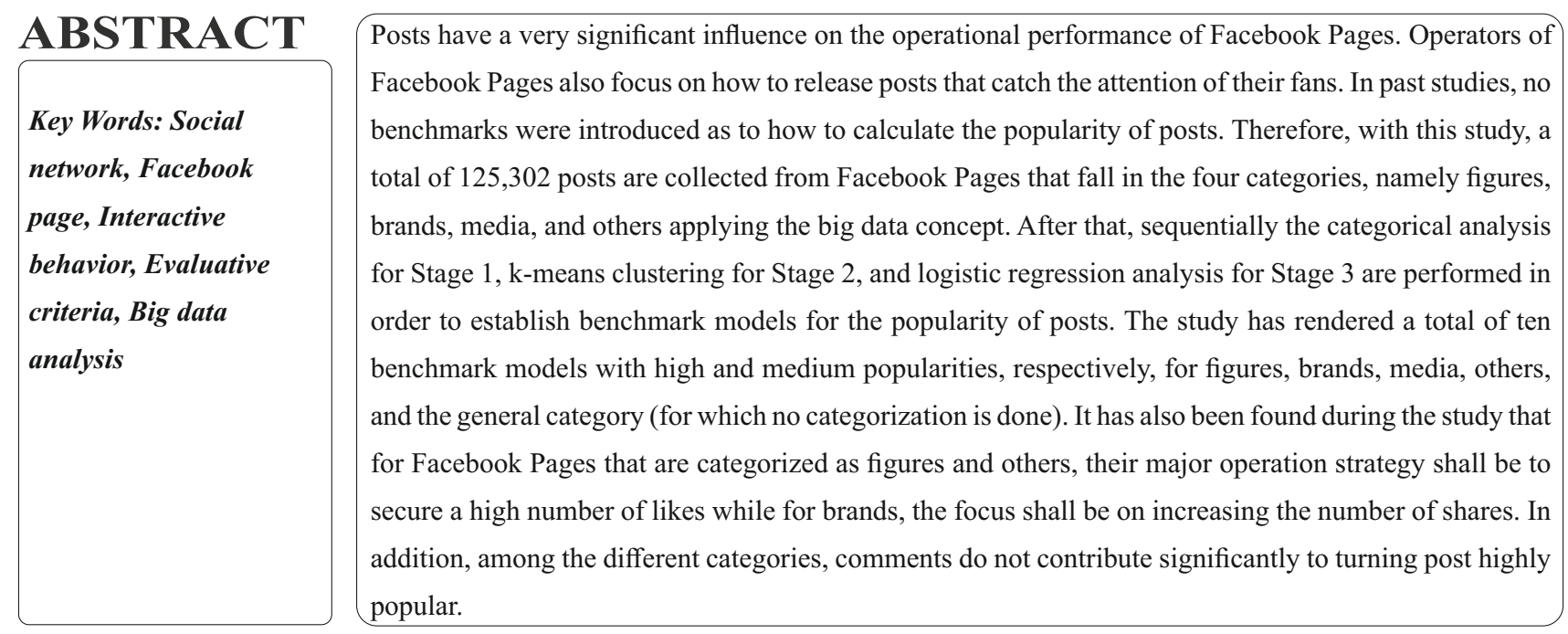

\section{Introduction}

As information technology and cloud technology quickly grow, the surge in the data size also marks the declaration of arrival of a big data era. The importance of big data analysis lies in its ability to manage, process, store, analyze, and transform huge and disorganized data into valuable information through statistical tools and to accordingly serve as reference and help governments, businesses, and individuals make a decision (Sauer, 2013). Nowadays, big data has been extensively applied in a variety of industries, such as education, medical care, retail sales, sports, finance, manufacturing, and business management and a new business model (Zhuge \& Sun, 2016)has been created in order to help improve corporate competitive advantages and to realize sustainable management. A key to whether a business can continue to exist or not lies in if it understands consumers. Taking advantage of the convenience brought about by mobile technology for people, however, businesses are able to know consumers' preferences, behaviors, and habits (Erevelles, Fukawa, \& Swayne, 2016; Tang \& Wu, 2015) to accordingly satisfy their needs and to fulfill maximum benefits of the business itself at the same time (Fang \& Li, 2014).

A social networking site serves exactly as the best platform to get to know the preferences, behaviors, and habits of consumers. A social networking site does not only provide information but also emphasize the interaction and sharing between the network platform and multiple users (O'Reilly, 2005). Such major technological change makes social networking sites loved by its users and hence 
becoming more and more popular. Many individual users, business owners, entertainers, store owners, and charity groups are taking advantage of social media to interact with other people (Nosko, Wood, \& Molema, 2010), to communicate their beliefs, to operate and sell products (Simona, Iuliana, Luigi, \& Mihai, 2013), and to engage themselves in marketing activities (Mangold \& Faulds, 2009) because of the dawn of a promising network-based era. Among the numerous social networking sites and media, Facebook has the most extensive and largest user base. Statistics by the fourth quarter of 2017 show that the number of monthly active users of Facebook already reached 2.2 billion, a growth of $16 \%$ from that in the fourth quarter of 2016. In addition, the number of daily active users reached 1.4 billion, accounting for $66 \%$ of monthly active users (Statista, 2018).

Due to its large number of users, huge base of viewers, and big market share, Facebook has created tremendous data. By analyzing user behaviors with the huge size of data, it does not only provide businesses with an idea on the strategy to operate social marketing but also help create a big data information bank to facilitate a forecast of products in the future or trends in preferred services. As such, businesses are willing to devote marketing budget and manpower to the operation of Facebook Pages; they want to enhance their brand and corporate images (de Vries, Gensler, \& Leeflang, 2012; Jahn \&Kunz, 2012). Nevertheless, many businesses are in the traditional mindset that "where people go, business follows" and overly emphasize the importance of the number of fans for their Facebook Pages (Lapoint, 2012). The number of fans without social behaviors that exist on Facebook Pages is greater than the highly social one. In other words, despite the large number of fans, they do not contribute much to the promotion of posts and communication of information, let alone catch people's attention. In addition, the popularity of posts is highly correlated to the operational efficacy of Facebook Pages. If the fans are unable to feel the value of a message conveyed on Facebook Pages, they will not interact (such as pressing likes, leaving comments, and sharing), let alone engaging nonmembers of Facebook Pages in the conversation. That being said, how to create a highly attractive post so that more fans like Facebook Pages and follow them is also an issue of concern for researchers of social networking sites and the industry at the moment.

In the past, however, related studies of Facebook focused on the user side, such as the motives and purposes of getting involved in social networking sites (Foster, Francesucci, \& West, 2010; Nadkarni \& Hofmann, 2012; Raacke \& Bonds-Raacke, 2008), threatened privacy (Debatin, Lovejoy, Horn, \& Hughes, 2009), impacts on academic performance (Junco, 2012), analysis of personality traits of different types of users (Amichai-Hamburger \& Vinitzky, 2010; Mehdizadeh, 2010; Moore \& Mcelroy, 2012; Ryan \& Xenos, 2011), user behavior segmentation (Luarn, Kuo, Lin, Chiu, \& Jhan, 2018), preferred message contents (Chen, Chen, Chen, Chen, Yu, 2013; de Vries et al., 2012), among others. Few explored the practical essence and investigated the big data analysis from the perspectives of operators of Facebook Pages. Therefore, with the current study, the idea of big data is applied and the popularity benchmark models are created for the five categories, namely figures, brands, media, others, and the general category (without categorization) according to the number of likes, that of comments, and that of shares of Facebook Pages. The resultant post popularity benchmark models introduced through this study will not only serve as reference for operators of Facebook Pages but also facilitate the formation of effective operational policies.

\section{Theoretical Background}

\subsection{Social networking site}

Social networking sites are an Internet-based service and are meant to create an inter-personal relationship (Boyd \& Ellison, 2007; Rau, Gao \& Ding, 2008); they are referred to social media as well. An SNS uses a platform to create public or private personal 
data (gender, date of birth, domicile, education, siblings, email) so that one can extend his/her group of correlated friends. In addition, an SNS is equipped with features such as writing an article, sharing photos and videos, and live streaming; users enjoy a high level of freedom while operating a space helping shape their image and can interact with other users at any time.

Web 2.0 is an important basis for the development of an SNS (Zhou, 2011; Chen, Yen, \& Hwang, 2012) so that the site operation can shift towards a virtual community. A core idea of virtual community is persistent social interaction that requires cohesion and devotion of members of the community. By discussing and sharing information and developing common interests on line, social identity and affection result with time (Gutiérrez-Cillán, Camarero-Izquierdo, \& José-Cabezudo, 2017; Jin, Lee, \& Cheung, 2010). If members of a social community share the same goal or interest, a better interactive relationship can be obtained and valuable information transmission is possible by operating the social community (Jin et al., 2010). In addition, functionality, social interactivity, and entertainment are the most important factors for users to get involved in a social networking site (Sicilia \& Palazon, 2008). If an SNS is able to provide its members with valuable resources, it will improve the willingness of new members to take part and to refer others (Stuckey \& Barab, 2007). Due to the fact that an SNS can gather people relevant or similar to users together and obtain user behavioral information accordingly, it is used as an important tool (Verhoef \& Lemon, 2013) for businesses to collect information on products and services preferred by users and to accordingly develop surprising business opportunities (Moore \& McElroy, 2012).

In order to promote interaction among customers (Relling, Schnittka, Sattler, \& Johnen, 2016), businesses are gradually developing a new type of setting called virtual brand communities; the hope is to reinforce consumers' confidence (Kim, Sung, \&
Kang, 2014) in the brand through various types of effective interactive experiences and to accordingly bring about purchases (Hanna, Rohm, \& Crittenden, 2011; Hansen, Schneiderman, \& Smith, 2011). What businesses need, however, are persistent purchases from consumers, not one-time purchases. In other words, it is rather important as to how to keep consumers devoted to the virtual brand communities through an SNS. Sabate, Berbegal-Mirabent, Cañabate, and Lebherz (2014) believes that an SNS shall focus on three stages when it comes to marketing. First, it needs to know the prospective population. Then, the custom-made online content needs to be created. Finally, it needs to find a strategy suiTable for continuous publicity of the positive brand image (Heymann-Reder, 2011; Kilian \& Langner, 2010). In light of this, for the current study, popularity benchmark models for posts are created from the perspective of users and their interaction on Facebook Pages by pressing likes, leaving comments, and sharing the post to help operators of Facebook Pages effectively locate suiTable network-based marketing strategies.

\subsection{Facebook pages}

Facebook is a very popular SNS that enables not only release of posts, pictures, and status, but also real-time conversations with others through instantaneous messages (Holzner, 2008; Zhao, Grasmuck, \& Martin, 2008). Facebook also offers unique and interesting conditions so that users can engage in interaction of multiple selves and exploration while expressing themselves (Hollenbeck \& Kaikati, 2012). Facebook not only enables collection and sharing of ideas, comments, and opinions but also provides users sharing the same interest with access to online expression (Weber, 2009).

In addition, more and more businesses that care about social community-based marketing have found that an SNS can not only create a link between a business and its customers but also expand the business scale (Ruiz-Mafe, Marti-Parreño, \& SanzBlas, 2014). Therefore, Facebook is believed to be a 
most popular network-based media (Kang, Tang, \& Fiore, 2014; Sarwar, Haque, \& Yasmin, 2013). Facebook Pages, a feature introduced by Facebook, by the same token, has business development potential; it can help businesses enhance their brand attraction and catch users' attention (Lin \& Lu, 2011). Facebook Pages is not only a new platform for businesses (Khan et al., 2009) but also a developmental goal for many businesses and organizations while they devote related budget one after another. In the management of Facebook Pages, by posting advertising messages or contents that are valuable to users, it helps attract users to like Facebook Pages and become a fan. Users of Facebook Pages, on the other hand, not only are the content receiver and content producer at the same time but also control the influence over information flow and information transmission (Safko \& Brake, 2009). After users like Facebook Pages, they can receive posts, photos, videos, among other messages (Jahn \& Kunz, 2012), on their wall and can also interact with other fans of Facebook Pages by releasing posts, leaving comments, pressing likes, and sharing (Kim, 2013). Besides demonstrating support of the brand as such, fans can also simply discuss common interests and topics with other fans (Richter, Riemer, \& vom Brocke, 2011). In addition, users prefer liking Facebook Pages that have a huge number of "likes" and informative messages from experts (Jin, Phua, \& Lee, 2015). In other words, effective management of Facebook Pages and their efficacy are also part of the information that businesses are keen to know. The comprehensive messages provided on Facebook Pages can help members make more objective judgment about a business and its products/services (Flavián \& Guinalíu, 2006). For business owners, Facebook Pages is a tool ( $\mathrm{Lin} \& \mathrm{Lu}, 2011$ ) to market their own brands and products. The hope is to affect friends of existing fans on Facebook so that businesses can reach out to more potential customers (Paquette, 2009).

If users can be guided to like Facebook Pages of a certain brand and posts that interest and are valuable to users can be properly used for communication of information, there are significant opportunities to make the users become relatively adhesive fans, accordingly develop relatively high loyalty to the brand (Sahin, Zehir, \& Kitapçı, 2011), and relatively more acceptable of information provided by the brand (de Vries et al., 2012). Lin and $\mathrm{Lu}$ (2011) also points out that fans will continue to use and follow Facebook Pages if the business increases interaction and communication with users that helps create mutual trust. Strand (2011) also points out that Facebook Pages can help a business or a brand by serving as a communication bridge that links existing and prospective customers, which not only is conducive to creating a good customer relationship but also can entertain the fans. Besides, prior studies have indicated that fans that already like Facebook Pages of a brand visit its stores more often than those that have not and are more willing to leave positive feedback on line (Dholakia \& Durham, 2010; Gupta \& Harris, 2010). Through collection and exchange of information about a brand on Facebook, it helps not only improve the brand image and rights but also enhance consumers' intention to make purchases (Dehghani \& Tumer, 2015).

\subsection{Interactive Behavioral Tool of Facebook Pages}

Pressing likes, leaving comments, and sharing are the tools to interact with others on Facebook Pages. Pressing likes, in particular, is the most preferred one and also the commonly used one by fans. In the past, scholars believed that pressing likes cost the least because it did not take too much thinking or time while a "like" was being pressed yet the interaction was accomplished (Sabate et al., 2014). Therefore, sometimes, pressing likes is no longer just a way for fans to show their approval or liking of what is included in a message; it may have been just a habit of users to press likes for messages they have read. Regardless of what the fans think when pressing likes, however, their friends see the contents that they have liked and it exercises the effect of promotion. "Leaving comments" is a highly interactive feature. It means that fans are willing to 
discuss further and provide feedback on posts from operators of Facebook Pages and that they wish to exchange and interact with other fans through such messages as well (Kwok \& Yu, 2013). Prior studies have also shown that the level of interaction associated with leaving comments is higher than that of simply pressing likes, which means that the more comments there are, the more devoted fans are to Facebook Pages(de Vries et al., 2012; Kwok \& Yu, 2013; Pöyry, Parvinen, \& Malmivaara, 2013). It is pointed out in Sabate et al. (2014) study that the length of a post will not affect the willingness of fans to leave a comment. If there is a link in a post, however, it will. Because when users hit the link, it is relatively uneasy for them to come back to the original post to leave a comment. "Sharing", on the other hand, usually means that the fans believe that the content of a message is valuable and are highly approval of it. However, when fans decide to engage themselves in the sharing behavior, most of them will evaluate the content of the message, such as whether the message is worth spreading or not and whether it will become a talking point with friends or create an echo among friends or not (de Vries et al., 2012). Therefore, for fans, sharing, as compared to pressing likes and leaving comments, is the costliest.

In addition, Berger and Milkman (2012) study has shown that the more likely the content of a message is to trigger positive emotions in readers, the more likely they will share it. Therefore, if it is desired that Facebook Pages can be quickly promoted and made known to more people or attract new members to be enrolled, it is advised that most positive information should be posted; fans are willing to share wonderful things with their friends and enjoy the delight together (Walsh, Gwinner, \& Swanson, 2004). It has been proven through Berger and Milkman (2012)'s study, however, that negative posts would also enhance the willingness of readers to share. It is because negative posts arouse the empathy in their readers and motivate them to help by sharing to move more people and to give rise to substantial action. In addition, it has been found in the studies of de Vries et al. (2012) and Pöyry et al. (2013) that when fans obtain more entertaining contents through posts, they are usually inclined to press likes, leave a comment, and share (Civijikj \& Michahelles, 2013) and motivated to stay involved (Shao \& Ross, 2015). Among the Facebook Pages managed by businesses, however, relatively highly entertaining posts are not something anticipated by their fans. Fans hope that posts released by businesses contain information of relatively high practical value (Perez-Vega, Taheri, Farrington, \& O' Gorman, 2018). Kwok and Yu (2013), on the other hand, suggests that posts should primarily consist of photos plus written information if they are to win more likes, receive more comments, and be shared more frequently. Photos enable users to better internalize the message and content to be conveyed through a post so that they are more capable of writing out their feelings or opinions within a short period of time (Sabate et al., 2014). It is, however, not recommended to provide a link or clips of a video in a post without other written information.

\section{Methodology}

\subsection{Research stages}

This study aims to build popularity benchmark models for posts on Facebook Pages to accordingly provide operators of Facebook Pages with something to follow while promoting their posts. As such, data analysis is carried out in three stages for this study. For Stage 1, in order to precisely depict and create popularity benchmark models for posts in respective categories, Facebook Pages are divided into figures, brands, media, others, and general (without categorization), five categories in total for this study and the attributes and characteristics of posts in each of these categories are explored. For Stage 2, posts on Facebook Pages in respective categories are grouped through k-means clustering as an analytical approach; posts in each category are divided into three levels of popularity (Highly popular posts, Moderately popular posts, Minimally popular posts). The three major variables used to weigh the popularity of posts are Like, Comment, and Share (as shown in Table 1). For Stage 3, logistic regression analysis is applied to the results of 
grouping from Stage 2 and the benchmark model for popularity of posts is created for each of the five categories. Through the benchmark model, one can know the level a post belongs to and the probability for it to become highly popular or moderately popular.

Table 1. Definitions of Variables for Interaction among Users on Facebook Pages

\begin{tabular}{|c|c|}
\hline $\begin{array}{l}\text { Measuring } \\
\text { variables }\end{array}$ & Definitions of Variables \\
\hline Like & Total number of likes for popular posts (each user of Facebook Pages is entitled to one like at most) \\
\hline Comment & $\begin{array}{l}\text { Total number of comments for popular posts (It is not restricted that only one comment will be counted } \\
\text { for each user of Facebook Pages. If one user provides two different comments on one post, they will } \\
\text { count as two comments.) }\end{array}$ \\
\hline Share & Total number of shares for popular posts (each user of Facebook Pages is entitled to one share at most) \\
\hline
\end{tabular}

\subsection{Data Analysis Method}

\subsubsection{Cluster analysis}

Cluster analysis is a multi-variate analysis procedure where the distance between data is calculated through algorithm mainly based on the correlation of data and data that are relatively highly similar are assigned to the same group (Skarbinski et al., 2009). Therefore, the optimal results of grouping are that intra-group data share a high level of similarity and inter-group data show a relatively high level of heterogeneity. This approach is also referred to as natural grouping. Based on the analytical approach, clustering is further divided into three types, that is hierarchical, non-hierarchical, and two-step. Due to the fact that more than 200 posts on Facebook Pages have been under watch in this study and all of them are continuous variable-type of data, nonhierarchical clustering as advised by Johnson and Wichern (2007) is more suiTable. With nonhierarchical clustering, the most frequently adopted approach is k-means clustering (Wagstaff, Cardie, Rogers, \& Schrödl, 2001). Compared to hierarchical clustering, the extent of impacts from the outlier, the similarity measure, and unsuitable grouping variables on k-means clustering is relatively minimal (Liu, 2007). This is why, for grouping during Stage 2 of this study, k-means clustering is adopted. With k-means clustering, however, it is required to pre-set the number of clusters before the iterative method is adopted to find out the most suitable grouping that is applicable to a larger sample size. Therefore, in practical analysis, it is often performed multiple times in order to find a meaningful solution (Davidson \& Ravi, 2007). In this study, k-means clustering is applied to divide observed data into three clusters by the extent of popularity and each entry of data observed is gradually combined into the closest cluster of the three according to the approximate matrix formed by similarity or distance till there are no more observed data remaining.

\subsubsection{Logistic regression analysis}

It was found for this study during preview that data on Facebook Pages are abnormal and do not reflect general linear statistical application because the general linear regression and discriminant analyses could not be used to create the benchmark model for popular posts. Nevertheless, Warner (2008) believes that for logistic regression analysis, it is unnecessary to assume that data properties are normal and that homogeneous assumptions are not necessarily required for the variants between dependent variables $(\mathrm{Y})$ and independent variables $(\mathrm{X} 1 \mathrm{X} 2$ $\mathrm{X} 3 \ldots \mathrm{Xn}$ ). When it is impossible to change data properties, logistic regression, as compared to multiple regression and discriminant analyses, is a more suitable statistical method. Therefore, in this study, suggestions from prior scholars will be adopted. Logistic regression analysis will be used to build popularity benchmark models for posts on Facebook Pages.

\subsection{Sampling and participants}

In this study, the "Social Insight: Facebook Monitoring Service" database provided by the Institute for Information Industry in Taiwan will be 
used. The data covered include the number of likes, that of comments, and that of shares of each post in the rankings of Facebook Pages that belong to different categories. A total of 125,302 effective posts on Facebook Pages were collected between July 11, 2015 and July 23, 2016 for this study. The number of posts in a total of four categories, namely, figures, brands, media, and others is shown in Table 2. Meanwhile, subsequent study analyses are conducted according to the number of likes, that of

Table 2. Descriptive Statistics of Research Samples comments, and that of shares earned by each post.

In addition, normal testing is performed on the 125 , 302 posts in this study (as shown in Table 3). The Kolmogorov-Smirnov test shows that the distribution of the three independent variables is abnormal based on the fulfillment of a significance level in the normal assumption of likes, comments, and shares $(\mathrm{p}=.00<.05)$.

\begin{tabular}{|l|l|l|}
\hline Category & Posts & Percentage of posts \\
\hline figures & 34,256 & $27.30 \%$ \\
\hline brands & 40,175 & $32.10 \%$ \\
\hline media & 18,497 & $14.80 \%$ \\
\hline others & 32,374 & $25.80 \%$ \\
\hline general & 125,302 & $100 \%$ \\
\hline
\end{tabular}

Table 3. Kolmogorov-Smirnov test

\begin{tabular}{l|l|ll}
\hline & Kolmogorov-Smirnov test & & \\
\cline { 2 - 4 } & Statistics & $d f$ & p-value \\
\hline Like & 0.366 & 125301 & 0 \\
\hline Comment & 0.44 & 125301 & 0 \\
\hline Share & 0.434 & 125301 & 0 \\
\hline
\end{tabular}

\section{Results and Discussions}

\subsection{Grouping Results of Respective Categories}

Among posts that are about figures, 700 are categorized as highly popular and 5,204 are moderately popular while 28,352 are minimally popular. Among those that are about brands, 121 are categorized as highly popular and 1,820 are moderately popular while 38,234 are minimally popular. Among those that are about media, 155 are categorized as highly popular and 1,252 are moderately popular while 17,090 are minimally popular. Among those that are categorized as others, 395 are categorized as highly popular and 2,656 are moderately popular while 29,323 are minimally popular. Finally, among those that are categorized as general posts, 773 are categorized as highly popular and 7,507 are moderately popular while 117,022 are minimally popular.

In addition, ANOVA is used in this study to test if cluster benefits exist with likes, comments, and shares. Analysis results show that the F value of posts in respective categories and in the three clusters, namely highly popular, moderately popular, and minimally popular, consistently demonstrated significant differences $(p=.00<.05)$, indicating that the analysis is the result of effective clustering (as shown in Table 4). 


\section{Available at: www.imperialpublications.com}

Table 4. Summary of K-means Clustering and ANOVAAnalysis of Respective Categories

\begin{tabular}{|c|c|c|c|c|c|c|}
\hline \multirow{2}{*}{ Category } & \multirow{2}{*}{ Cluster } & \multicolumn{3}{|l|}{ Mean } & \multirow{2}{*}{$\begin{array}{l}\text { Number of } \\
\text { posts }\end{array}$} & \multirow{2}{*}{ Name } \\
\hline & & Like & Comment & Share & & \\
\hline \multirow{5}{*}{ figures } & 1 & 143189.96 & 1589.76 & 2877.96 & 700 & Highly popular \\
\hline & 2 & 37856.84 & 549.66 & 633.04 & 5,204 & Moderately popular \\
\hline & 3 & 4971.27 & 128.37 & 104.13 & 28,352 & Minimally popular \\
\hline & $\mathrm{F}$ & 58947.786 & 434.729 & 1113.87 & & \\
\hline & P-value & 0.00 & 0.00 & 0.00 & & \\
\hline \multirow{5}{*}{ brands } & 1 & 45147.27 & 2289.98 & 9329.8 & 121 & Highly popular \\
\hline & 2 & 10865.9 & 507.76 & 952.61 & 1,820 & Moderately popular \\
\hline & 3 & 799.73 & 123.18 & 139.22 & 38,234 & Minimally popular \\
\hline & $\mathrm{F}$ & 63919.921 & 1237.831 & 7344.343 & & \\
\hline & P-value & 0.00 & 0.00 & 0.00 & & \\
\hline \multirow{5}{*}{ media } & 1 & 81929.32 & 3390.42 & 28195.71 & 155 & Highly popular \\
\hline & 2 & 24371.64 & 1034.69 & 5204.34 & 1,252 & Moderately popular \\
\hline & 3 & 2164.52 & 103.22 & 401.85 & 17,090 & Minimally popular \\
\hline & $\mathrm{F}$ & 30515.746 & 2046.117 & 4968.093 & & \\
\hline & P-value & 0.00 & 0.00 & 0.00 & & \\
\hline \multirow{5}{*}{ others } & 1 & 39956.66 & 1586.99 & 4711.32 & 395 & Highly popular \\
\hline & 2 & 10565.14 & 405.26 & 2047.18 & 2656 & Moderately popular \\
\hline & 3 & 827.31 & 47.89 & 174.78 & 29323 & Minimally popular \\
\hline & $\mathrm{F}$ & 73395.794 & 743.897 & 4437.414 & & \\
\hline & P-value & 0.00 & 0.00 & 0.00 & & \\
\hline \multirow{5}{*}{ general } & 1 & 140412.81 & 1711.52 & 5047.97 & 773 & Highly popular \\
\hline & 2 & 35246.3 & 746.16 & 1994.29 & 7507 & Moderately popular \\
\hline & 3 & 2300.98 & 113.37 & 236.85 & 117022 & Minimally popular \\
\hline & $\mathrm{F}$ & 216461.09 & 2149.83 & 4076.69 & & \\
\hline & P-value & 0.00 & 0.00 & 0.00 & & \\
\hline
\end{tabular}

\subsection{Suitability Testing of Respective Categories}

In this study, the suitability of the null model and the full model is evaluated according to the clustering outcome from Stage 1 in order to further verify the accuracy of k-means clustering and to create popularity benchmark models for posts. First of all, the suitable model adopted in this study is the null model (the smallest model) that contains only the constant terms and the full model (the largest model) that contains all independent variables. The suitability analyses of respective categories are shown in Table 5.

In the category of figures, the AIC of the null model is 35790.307 ; the BIC is 35807.190 ; the $-2 \log$ likelihood is 35786.307 while the AIC of the full model is 25.482; the BIC is 93.015, the $-2 \log$ likelihood is 9.482 , and $x^{2}=35776.825(\mathrm{p}=.00<$ $.05)$. In the category of brands, the AIC of the null model is 16459.183 ; the $\mathrm{BIC}$ is 16476.385 ; the $-2 \log$ likelihood is 16455.183 while the AIC of the full model is 16250.416 ; the $\mathrm{BIC}$ is 16319.224 , the $-2 \log$ likelihood is 16234.416 , and $x^{2}=220.766(\mathrm{p}=.00<$ $.05)$. In the category of media, the AIC of the null model is 10933.491; the BIC is 10949.142 ; the $-2 \log$ likelihood is 10929.491 while the AIC of the full model is 6871.223; the BIC is 6933.826, the $-2 \log$ likelihood is 6855.223 , and $x^{2}=4074.268(\mathrm{p}=.00<$ $.05)$. In the category of others, the AIC of the null model is 22572.739; the BIC is 22589.510 ; the $-2 \log$ likelihood is 22568.739 while the AIC of the full 
model is 24.904; the BIC is 91.985, the $-2 \log$ likelihood is 8.904 , and $x^{2}=22559.835(\mathrm{p}=.00<$ .05). Finally, in the category of general, the AIC of the null model is 66143.697; the BIC is 66163.174; the $-2 \log$ likelihood is 66139.697 while the AIC of the full model is 32.127 ; the $\mathrm{BIC}$ is 110.035 , the -2 $\log$ likelihood is 16.127 , and $x^{2}=66123.57(\mathrm{p}=.00<$ $.05)$.Results of the study show that among the number of likes, that of comments, and that of shares

Table 5. Suitability Testing of Respective Categories as independent variables, at least one of them can effectively forecast the probability value of the outcome variable.

As far as the AIC and BIC values of the null model and the full model of respective categories are concerned, they dropped a lot in the full model and 2 consistently reached significance. This shows that the applied independent variables contributed tremendously to the overall model.

\begin{tabular}{|c|c|c|c|c|c|c|c|}
\hline \multirow{2}{*}{ Category } & \multirow{2}{*}{ Model } & \multicolumn{3}{|c|}{ Appropriate model criteria } & \multicolumn{3}{|c|}{ Likelihood ratio } \\
\hline & & AIC & $\mathrm{BIC}$ & -2 Log Likelihood & $\chi^{2}$ & $d f$ & p-value \\
\hline \multirow{2}{*}{ figures } & Null & 35790.307 & 35807.19 & 35786.307 & & & \\
\hline & Full & 25.482 & 93.015 & 9.482 & 35776.825 & 6 & 0 \\
\hline \multirow{2}{*}{ brands } & Null & 16459.183 & 16476.385 & 16455.183 & & & \\
\hline & Full & 16250.416 & 16319.224 & 16234.416 & 220.766 & 6 & 0 \\
\hline \multirow{2}{*}{ media } & Null & 10933.491 & 10949.142 & 10929.491 & & & \\
\hline & Full & 6871.223 & 6933.826 & 6855.223 & 4074.268 & 6 & 0 \\
\hline \multirow{2}{*}{ others } & Null & 22572.739 & 22589.51 & 22568.739 & & & \\
\hline & Full & 24.904 & 91.985 & 8.904 & 22559.835 & 6 & 0 \\
\hline \multirow{2}{*}{ general } & Null & 66143.697 & 66163.174 & 66139.697 & & & \\
\hline & Full & 32.127 & 110.035 & 16.127 & 66123.57 & 6 & 0 \\
\hline
\end{tabular}

4.3 Logistic Regression Analysis of Respective Categories

Posts whose popularity is low among the five categories, namely figures, brands, media, others, and general (without categorization) are set as the reference in this study and logistic regression analysis is performed (as shown in Table 6). The significance level of the p-value in Table 6 shows that variables, that is, likes, comments, and shares, in respective categories consistently have significant forecast power in both posts whose popularity is high and medium.

Analysis results of respective categories show that the odds ratio of likes, comments, and shares of posts whose popularity is high in the category of figures is $1.122,1.000$, and 1.002, respectively while that of those of posts whose popularity is medium is 1.101, 1.001 , and 1.002 , respectively. This shows that in order for posts in the category of figures to become highly or moderately popular, the number of likes should be increased as it enhances the odds ratio, too. The odds ratio of likes, comments, and shares of posts whose popularity is high in the category of brands, on the other hand, is 1.001, 0.998, and 1.005, respectively while that of those of posts whose popularity is medium is $1.001,1.000$, and 1.001 , respectively. Therefore, in order for posts in the category of brands to become highly popular, the number of shares needs to be increased first. The odds ratio of likes, comments, and shares of posts whose popularity is high in the category of media, is $1.000,1.000$, and 1.001 , respectively while that of those of posts whose popularity is medium is consistently 1.000. Therefore, in order for posts in the category of media to become highly popular, the number of shares also needs to be increased. The odds ratio of likes, comments, and shares of posts whose popularity is high in the category of others, is $1.344,1.014$, and 1.057 , respectively while that of 
those of posts whose popularity is medium is 1.328 , 1.013 , and 1.056, respectively. In other words, for a post in the category of others to become highly popular, the number of likes shall be increased.

Finally, the odds ratio of likes of posts whose popularity is high in the general category is 1.172 , which means that for a post to become highly popular in the general category, the odds increase by $17.2 \%$ for each unit of likes added. For comments, on the other hand, the odds ratio is 1.004 , indicating that for a post to become highly popular, the odds increase by $0.4 \%$ for each unit of comments added. The odds ratio of shares is 1.008 . That is, for a post to become highly popular, the odds increase by $0.8 \%$ for each unit of shares added. As far as posts whose popularity is medium are concerned, on the other hand, the odds ratio of likes, comments, and shares is $1.155,1.003$, and 1.007 , respectively. In addition, what is being tested with the Wald test is the square of the statistical size of $\mathrm{z}$. When freedom is 1 , the Wald value will be close to Chi-squared distribution. Therefore, when $\alpha=.05$ and the Wald value is greater than 3.84 , significance is reached.

Table 6. Summary of Regression Analyses of Respective Categories

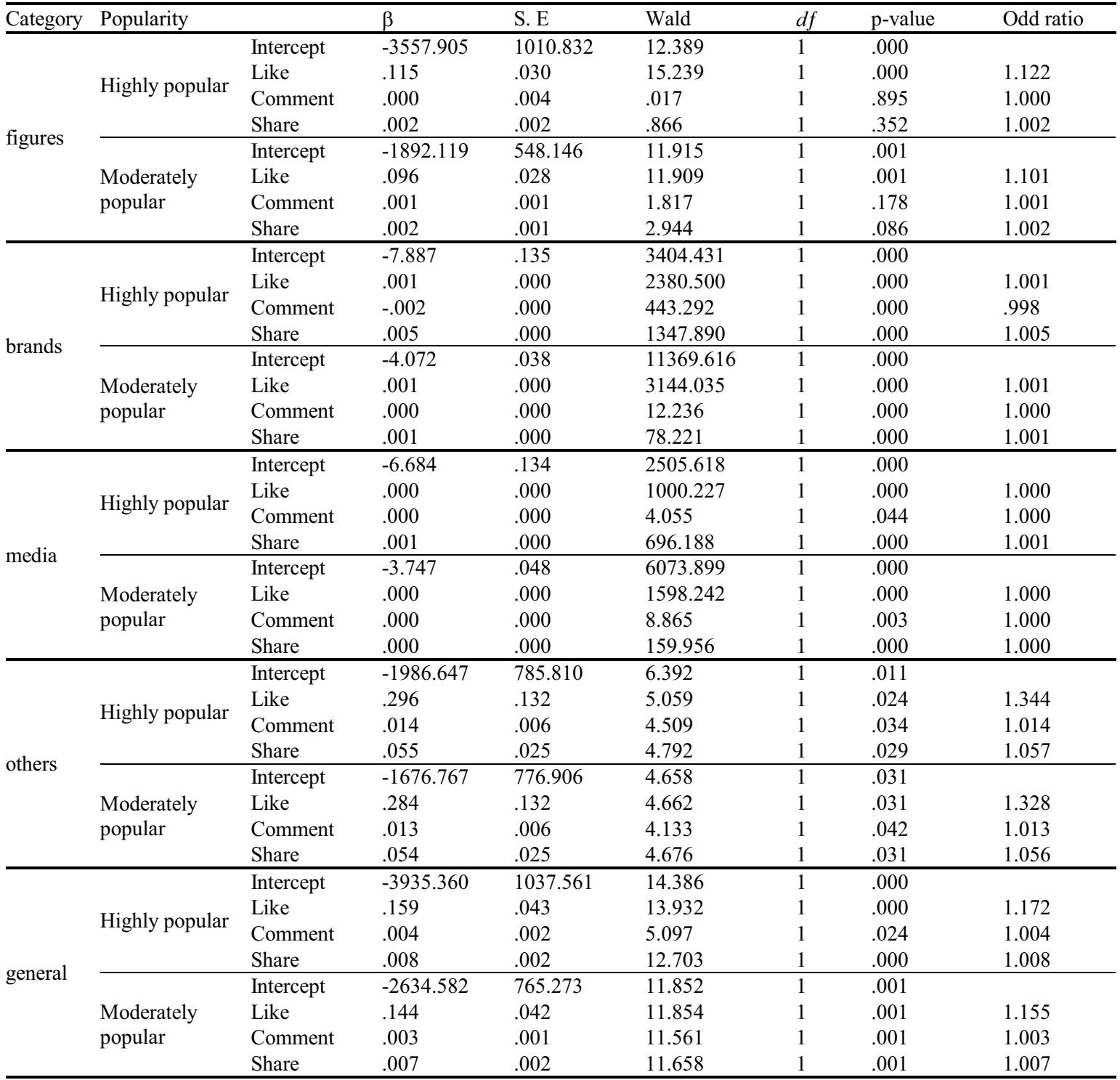

Reference group: Minimally popularity 


\subsection{Benchmark model for the popularity of posts in respective categories}

The benchmark model for the popularity of posts in respective categories is sorted out in this study through the study results shown in Table 6 . After the number of likes, comments, and shares of posts is introduced into the benchmark model, the chances for posts to fulfill the extent of popularity can be obtained.

\section{(1) Figures :}

Highly popular posts

$$
\ln (p / 1-p)=-3557.905+(0.115 * \text { Likes })
$$

Moderately popular posts

(2)

$$
\ln (p / 1-p)=-1892.119+(0.096 * \text { Likes })
$$

Highly popular ost

$$
\ln (\mathrm{p} / 1-\mathrm{p})=-7.887+(0.001 * \text { Likes })-
$$

$(0.002 *$ Comments $)+(0.005 *$ Shares $)$

Moderately popular posts $\ln (\mathrm{p} / 1-\mathrm{p})=-4.072+(0.001 *$ Likes $)-(0 *$

Comments $)+(0.001 *$ Shares $)$

(3) Media :

Highly popular posts $\ln (\mathrm{p} / 1-\mathrm{p})=-6.684+(0 *$ Likes $)+(0 *$

Comments $)+(0.001 *$ Shares $)$

Moderately popular posts $\ln (\mathrm{p} / 1-\mathrm{p})=-3.747+(0 *$ Likes $)+(0 *$ Comments $)+(0 *$ Shares $)$

(4) Others :

Highly popular posts $\ln (\mathrm{p} / 1-\mathrm{p})=-1986.647+(0.296 *$ Likes $)+(0.014 *$

Comments $)+\left(0.055^{*}\right.$ Shares $)$

Moderately popular posts $\ln (\mathrm{p} / 1-\mathrm{p})=-1676.767+(0.284 *$ Likes $)+\left(0.013^{*}\right.$

Comments $)+(0.054 *$ Shares $)$

(5) General :

Highly popular posts $\ln (\mathrm{p} / 1-\mathrm{p})=-3935.360+(0.159 *$ Likes $)+(0.004 *$

Comments $)+(0.008 *$ Shares $)$

Moderately popular posts $\ln (\mathrm{p} / 1-\mathrm{p})=-2634.582+(0.144 *$ Likes $)+(0.003 *$

Comments $)+(0.007 *$ Shares $)$

\section{Conclusions and Implications}

\subsection{Conclusions}

This study aims to create the benchmark model for the popularity of posts on Facebook Pages. Therefore, in this study, the three types of interactions, namely, the number of likes, that of comments, and that of shares, in the Facebook community are used for the analysis. Due to the fact that data are non-normally distributed, logistic regression analysis is adopted in this study in order to create the benchmark model for Facebook Pages in different categories, namely figures, brands, media, others, and general posts. In this study, posts whose popularity is low in respective categories are used as the reference group. In other words, for each category, there are two benchmark models, that is, one for high popularity and the other for medium popularity. In total, there are ten benchmark models. After the number of likes, that of comments, and that of shares of posts are introduced into the logistic regression benchmark model, the chances for posts to fulfill the extent of popularity can be obtained. As far as probability theory is concerned, if the probability is $1 / 2$, the possibility for an event to occur and not to occur is 50/50 (Hosmer \& Lemeshow, 1989). Therefore, we can infer that once the number of likes, that of comments, and that of shares are introduced into a benchmark model for high popularity, the closer the obtained probability is to 1 , the more likely it is to forecast that the specific post will become a highly popular one.

In the benchmark model for popular posts in the category of figures, it is found that the number of comments and that of shares cannot effectively forecast posts whose popularity varies. Only the number of likes can effectively forecast popular posts on Facebook Pages that are categorized as figures. Therefore, it is advised that the focus should be placed on increasing the number of likes in the management of Facebook Pages that are categorized as figures. In the benchmark model for posts in the category of brands, on the other hand, it is found that the focus needs to be placed on reinforcing the number of shares in order for an article to become highly popular on Facebook Pages that are categorized as brands. As compared to the number of likes and that of comments, in the management of Facebook Pages that are categorized as brands, for a post to become highly or moderately popular, the number of comments, relatively speaking, does not 
help much. Analysis results of the benchmark model for posts in the category of media are relatively special. It is found in analysis results that the regression coefficients of the number of likes, that of comments, and that of shares are closer to 0 but the regression coefficient for the number of shares is slightly higher. It is advised that operators of Facebook Pages in the category of media can focus on increasing the number of shares by emphasizing the quality of posts so that users of the Facebook Pages are more willing to share them. As far as posts in the category of others are concerned, it is advised that operators of Facebook Pages prioritize increasing the number of likes before the number of shares and lastly that of comments. Finally, for general posts, increasing the number of likes, that of comments, and that of shares is consistently associated with very high probabilities in turning the posts into highly and moderately popular ones. From the perspective of regression coefficient, the increase in the number of likes as compared to the number of comments and that of shares can more quickly enhance the publicity of posts. To sum up, it is found through this study that comments do not bring about significant benefits in terms of turning posts in different categories into highly popular ones. In order to maximize popularity, increasing the number of likes and that of shares remains preferred strategies.

\subsection{Implications}

The ten benchmark models created through this study for popularity of posts show that depending on the categories the posts are in, interactive behavior (Like Comment Share) to be prioritized differs somewhat differently in order for them to become highly popular. For brands, for example, the interactive behavior of sharing shall be emphasized first. For figures and others, on the other hand, the focus shall be placed on increasing the number of likes. Results and findings of this study answer to Sabate et al. (2014)'s point of view. Although both likes and comment are interactive behaviors, they exercise different effects as far as social media is concerned and hence separate testing is needed. As such, it is advised that operators of Facebook Pages should follow the categorized properties of Facebook Pages by engaging in different types of primary interactive behaviors in order to effectively improve the popularity of posts.

It was found through prior studies that releasing films was used as a means to increase the number of likes but it did not affect the number of comments. Therefore, it is advised that more time should be spent on producing films if increasing the number of likes is the only goal when it comes to management of Facebook Pages (Sabate et al., 2014). In addition, for the contents of posts, it is advised to present both text and photos in order to attract attention from the users and to accordingly increase the number of likes and that of comments (Kwok \& Yu, 2013). For Facebook Pages in different categories, however, the nature of posts will also affect the extent of interaction among fans. Facebook Pages that are operated by businesses, for example, cannot arouse highly interactive behaviors and involvement among their fans through relatively highly entertaining posts. Posts that are relatively highly practical, on the other hand, can better inspire proactive interactive behaviors (Gutiérrez-Cillán et al., 2017) in fans and their motives to remain involved. Therefore, it is advised that operators need to define the position of Facebook Pages created in order to improve the popularity of posts by releasing suitable posts that reflect preferences of their fans and to accordingly constantly stay at top on the dynamic wall of friends and to gain effective promotion.

Results of the study also show that the benefits of comments are inferior to those of likes and shares. In other words, in practical application, more incentives should be introduced so that fans focus on the interactive behaviors of "liking and sharing." At present, many operators of Facebook Pages are maximizing the popularity of their posts by asking fans to "like+leave a comment+share" or "like+leave a comment". Fans, however, often feel that it is complicated and hence give up on the 
interaction because of the sophisticated action that needs to be taken. It is hence advised through this study that operators of Facebook Pages adopt the benchmark models provided herein and first introduce the number of likes, that of comments, and that of shares of existing posts into the benchmark models in order to understand the probability currently obtained before deciding on which interactive behavior for fans to focus on so that burden of use may be minimized for the fans. In addition, applying the concept of odds ratio, 50 and 100 likes, comments, or shares are gradually obtained in order to understand if increasing the said unit quantity can significantly enhance the probability of a post to become highly popular. In addition, while evaluating promotional efficacy of Internet celebrities or Facebook Pages sponsored by manufacturers, it is advised to adopt the benchmark models for popularity of posts created in this study and adopt strategic combination of interaction with fans online and offline (such as posting previews online and meeting with fans offline) so that fans are willing to increase their involvement on Facebook Pages. Not only that the number of likes, that of comments, and that of shares may be increased to fulfill the purpose of promotion, more effective marketing strategies and tactics may be established for the promotion and advertising of commodities.

\section{References}

Amichai-Hamburger, Y., \& Vinitzky, G. (2010). Social network use and personality. Computers in Human Behavior, 26, 1289-1295.

Berger, J., \& Milkman, K. L. (2012). What makes online content viral? Journal of Marketing Research, XLIX, 192-205.

Boyd, D. M., \&; Ellison, N. B. (2007). Social network sites: Definition, history, and scholarship. Journal of Computer-Mediated Communication, 13(1), 210-230.

Chen, C. Y., Chen, T. H., Chen, Y. H., Chen, C. L., \& Yu, S. E. (2013). The spatio-temporal distribution of different types of messages and personality traits affecting the eWOM of Facebook. Natural Hazards, 65(3), 2077-2103.

Chen, S. C., Yen, D. C., \& Hwang, M. I. (2012). Factors influencing the continuance intention to the usage of Web 2.0: An empirical study. Computers in Human Behavior, 28(3), 933-941.

Cvijikj, I. P., \& Michahelles, F. (2013). Online engagement factors on Facebook brand pages. Social Network Analysis and Mining, 3(4), 843861.

Davidson, I., \& Ravi, S. S. (2007). The complexity of nonhierarchical clustering with instance and cluster level constraints. Data Mining and Knowledge Discovery, 14(1), 25-61.

de Vries, L., Gensler, S., \& Leeflang, P. S. H. (2012). Popularity of brand posts on brand fan pages: an investigation of the effects of social media marketing. Journal of Interactive Marketing, 26(2), 83-91.

Debatin, B., Lovejoy, J. P., Horn, A., \& Hughes, B. N. (2009). Facebook and online privacy: attitudes, behaviors, and unintended consequences. Journal of Computer-Mediated Communication, 15(1), 83-108.

Dehghani, M., \& Tumer, M. (2015). A research on effectiveness of Facebook advertising on enhancing purchase intention of consumer. Computers in Human Behavior, 49, 597-600.

Dholakia, U. M., \& Durham, E. (2010). One café chain's Facebook experiment. Harvard Business Review, 88(3), 26.

Erevelles, S., Fukawa, N., \& Swayne, L. (2016). Big Data Consumer Analytics and the Transformation of Marketing. Journal of Business Research, 69(2), 897-904.

Fang, Z. L., \& Li, P. J. (2014). The Mechanism of "Big Data" Impact on Consumer Behavior. American Journal of Industrial and Business Management, 4(1), 45-50.

Flavián, C., \& Guinalíu, M. (2006). Consumer trust, perceived security and privacy policy: Three basic elements of loyalty to a web site. Industrial Management \& Data Systems, 106(5), 601-620.

Foster, M. K., Francesucci, A., \& West, B. C. (2010). Why user participate in online social network. International Journal of e-Business Management, 4(1), 3-19.

Gupta, P., \& Harris, J. (2010). How e-WOM recommendations influence product consideration and quality of choice: A motivation to process information perspective. Journal of Business Research, 63(9-10), 1041-1049.

Gutiérrez-Cillán, J., Camarero-Izquierdo, C., JoséCabezudo, R. S. (2017). How brand post content contributes to user's Facebook brand-page 
engagement. The experiential route of active participation. Business Research Quarterly, 20(4), 258-274.

Hanna, R., Rohm, A., \& Crittenden, V. L. (2011). We're all connected: the power of the social media ecosystem. Business Horizons 54, 265-273.

Hansen, D. L., Schneiderman, B., \& Smith, M. A. (2011). Analyzing social media networks with NodeXL: insights from a connected world. M. Kaufmann, Amsterdam; Boston.

Heymann-Reder, D. (2011). Social media marketing: strategien für Sie und Ihr Unternehmen. Addison Wesley in Pearson Education Deutschland, München.

Hollenbeck, C. R., \& Kaikati, A. M. (2012) Consumers' use of brands to reflect their actual and ideal selves on Facebook. International Journal of Research in Marketing, 29(4), 395-405.

Holzner, S. (2008). Facebook marketing: Leverage social media to grow your business. Indiana, IN: Pearson Education.

Hosmer, D. W., \& Lemeshow, S. (1989). Applied logistic regression. New York: John Wiley \& Sons, Inc.

Jahn, B., \& Kunz, W. (2012). How to transform consumers into fans of your brand. Journal of Service Management, 23(3), 344-361.

Jin, S. V., Phua, J., \& Lee, K. M. (2015). Telling stories about breastfeeding through Facebook: The impact of user-generated content (UGC) on probreastfeeding attitudes. Computers in Human Behavior, 46, 6-17.

Jin, X.L., Lee, M.K.O., \& Cheung, C.M.K. (2010). Predicting continuance in online communities: model development and empirical test. Behaviour \& Information Technology, 29(4), 383-394.

Johnson, R. A. \& Wichern, D. W. (2007). Applied multivariate statistical analysis. (6th Ed.). NJ: Pearson Prentice Hall.

Junco, R. (2012). Too much face and not enough books: the relationship between multiple indices of facebook use and academic performance. Computers in Human Behavior, 28(1), 187-198.

Kang, J., Tang, L., \& Fiore, A. M. (2014). Enhancing consumer-brand relationships on restaurant Facebook fan pages: Maximizing consumer benefits and increasing active participation. International Journal of Hospitality Management, 36, 145-155.

Khan, I., Weishaar, B., Polinsky, L., Karasyov, V., Wei, D., Bazhenova, E., \& Hong, A. (2009). Nothing but net 【Adobe Digital Editions version】.
$R$ e trieved

fro $m$

http://www.capital.bg/getatt.php?filename $=0 \quad 68$ 5474.pdf

Kilian, T., \& Langner, S. (2010). Online-Kommunikation: Kunden zielsicher verführen und beeinflussen. Gabler, Wiesbaden.

Kim, E., Sung, Y., \& Kang, H. (2014). Brand followers' retweeting behavior on Twitter: How brand relationships influence brand electronic word-ofmouth. Computers in Human Behavior, 37, 18-25.

Kim, J. (2013). Relationship between Facebook usage and self-efficacy among collegiate athletes. Media Watch, 4(3), 364-374.

Kwok, L., \& Yu, B. (2013). Spreading social media messages on Facebook: an analysis of restaurant business to consumer communications. Focus on Information Technology, 54(1), 84-94.

LaPointe, P. (2012). Measure Facebook's impact on marketing: The proverbial hits the fans. Journal of Advertising Research, 52(3), 226-287.

Lin, K. Y., \& Lu, H. P. (2011). Intention to continue using Facebook fan pages from the perspective of social capital theory. Cyberpsychology, Behavior, and Social Networking, 14(10), 565-570.

Liu, B. (2007). Web data mining: Exploring hyperlinks, contents, and usage data. Heidelberg: Springer.

Luarn, P., Kuo, H. C., Lin, H. W., Chiu, Y. P., \& Jhan, Y. C. (2018). Analyzing user preferences using Facebookfan pages. Interfaces, 48(2), 166-175.

Mangold, W. G., \& Faulds, D. J. (2009). Social media: The new hybrid element of the promotion mix. Business Horizons, 52, 357-365.

Mehdizadeh, S. (2010). Self-presentation 2.0: Narcissism and self-esteem on Facebook. Cyberpsychology, Behavior, and Social Networking, 13(4), 357-364.

Moore, K., \& McElroy, J. C. (2012). The influence of personality on facebook usage, wall postings, and regret. Computers in Human Behavior, 28, $267-$ 274.

Nadkarni, A., \& Hofmann,S. G. (2012). Why do people use facebook? Personality \& Individual Differences, 52(3), 243-249.

Nosko, A., Wood, E., \& Molema, S. (2010). All about me: Disclosure in online social networking profile: The case of facebook. Computers in Human Behavior, 26, 406-418.

O'Reilly, T. (2005) What is web 2.0? Design patterns and business models for the next generation of software, 1st, Cambridge, MA: O'Reilly Media.

Paquette, D. E. (2009). Use of technology in the orthodontic practice: A day in the life. American Journal of Orthodontics and Dentofacial 
Orthopedics, 136(4), 607-610.

Perez-Vega, R., Taheri, B., Farrington, T., \& O'Gorman, $K$. (2018). On being attractive, social and visually appealing in social media: The effects of anthropomorphic tourism brands on Facebook fan pages. Tourism Management, 66, 339-347.

Pöyry, E., Parvinen, P., \& Malmivaara, T. (2013). Can we get from liking to buying? Behavioral differences in hedonic and utilitarian Facebook usage. Electronic Commerce Research and Applications, 12, 224-235.

Raacke, J., \& Bonds-Raacke, J. (2008). Myspace and Facebook: applying the uses and gratifications theory to exploring friend-networking sites. Cyberpsychology \& Behavior, 11(2), 169-174.

Rau P. P., Gao, Q., \& Ding Y. (2008). Relationship between the level of intimacy and lurking in online social network services. Computer Human Behavior, 24(6) 2757-2770.

Relling, M., Schnittka, O., Sattler, H., Johnen, M. (2016). Each can help or hurt: negative and positive word of mouth in social net-work brand communities. International Journal of Research in Marketing, 33(1), 42-58.

Richter, D., Riemer, K., \& vom Brocke, J. (2011). Internet social networking: Research state of the art and implications for enterprise 2.0. Business \& Information Systems Engineering, 3(2), 89-101.

Ruiz-Mafe, C., Marti-Parreño, J., \& Sanz-Blas, S. (2014). Key drivers of consumer loyalty to Facebook fan pages. Online Information Review, 38(3), 362380 .

Ryan, T., \& Xenos, S. (2011). Who uses facebook? An investigation into the relationship between the big five, shyness, narcissism, loneliness, and facebook usage. Computers in Human Behavior, 27(5), 1658-1664.

Sabate, F., Berbegal-Mirabent, J., Cañabate, A., \& Lebherz, P. R. (2014). Factors influencing popularity of branded content in Facebook fan pages. European Management Journal, 32(6), 1001-1011.

Safko, L. \&; Brake, D. K. (2009). The Social media Bible: Tactics, tools \&; strategies for business success. Hoboken, NJ: John Wiley \&; Sons, Inc

Sahin, A., Zehir, C., \& Kitapçı, H. (2011). The effects of brand experiences, trust and satisfaction on building brand loyalty; An empirical research on global brands. Procedia-Social and Behavioral Sciences, 24, 1288-1301.

Sarwar, A., Haque, A., \& Yasmin, F. (2013). The usage of social network as a marketing tool: Malaysian Muslim consumers' perspective. International Journal of Academic Research in Economics and Management Sciences, 2(1), 93-102.

Sauer, C. (2013). Big Data. Credit Union Magazine, 79(10), 28-32.

Shao, W., and Ross, M., 2015. Testing a conceptual model of Face-book brand page communities. Journal of Research in Interactive Marketing, 9(3), 239-258.

Sicilia, M., \& Palazón, M. (2008). Brand communities on the internet: A case study of Coca-Cola's Spanish virtual community. Corporate Communications: An International Journal, 13(3), 255-270.

Simona, V., Iuliana, C., Luigi, D., \& Mihai, T. (2013). The effects of social media marketing on online consumer behavior. International Journal of Business and Management, 8(14), 66-79.

Skarbinski, J., Ouma, P. O., Causer, L. M., Kariuki, S. K., Barnwell, J. W., Alaii, J. A., ...Hamel, M. J. (2009). Effect of malaria rapid diagnostic tests on the management of uncomplicated malaria with artemether-lumefantrine in Kenya: A cluster randomized trial. The American journal of tropical medicine and hygiene, 80(6), 919-926.

Statista (2018). Number of daily active Facebook users worldwide as of 4th quarter 2017 (in millions). Retrieved from https://www.statista.com/statistics/264810 Inumber-of-monthly-active-facebookusers-worldwidel

Strand, J. L. (2011). Facebook: Trademarks, fan pages, and community pages. Intellectual Property and Technology Law Journal, 23(1), 10-13.

Stuckey, B., \& Barab, S. (2007). New conceptions for community design. In R. N. L. Andrews \& C.Haythornthwaite (Eds.), The SAGE handbook of e-learning research (pp. 439465). Los Angeles: Sage.

Tang, M., \& Wu, Z. (2015). Research on the Mechanisms of Big Data on Consumer Behavior Using the Models of C2C E-Commerce and Countermeasures. African Journal of Business Management, 9(1), 18-34.

Verhoef, P. C., \& Lemon, K. N. (2013) Successful customer value management: key lessons and emerging trends. European Management Journal, 31(1), 1-15.

Wagstaff, K., Cardie, C., Rogers, S., \& Schroedl, S. (2001). Constrained K-means clustering 
with background knowledge. Proceedings of the Eighteenth International Conference on Machine Learning, 577-584.

Walsh, G., Gwinner, K., \& Swanson, S. R. (2004). What makes mavens tick? Exploring the motives of market mavens' initiation of information diffusion. Journal of Consumer Marketing, 21(2), 109-122.

Warner (2008). Applied statistics: From bivariate through multivariate techchniques. Thousand Oaks, CA: Sage.

Weber, L. (2009). Marketing to the social web: How digital customer communities build your business. Hoboken, NJ: John Wiley \& Sons.

Zhao, S., Grasmuck, S., \& Martin, J. (2008). Identity construction on Facebook: Digital empowerment in anchored relationships. Computers in Human Behavior, 24(5), 1816-1836.

Zhou, T. (2011). Understanding online community user participation: A social influence perspective. Internet Research, 21(1), 6781.

Zhuge, H., \& Sun, X. (2016). Semantics, Knowledge and Grids on Big Data. Future Generation Computer Systems, 64, 163-164. 